\title{
Time course of exercise capacity, skeletal and respiratory muscle performance after heart-lung transplantation
}

\author{
N. Ambrosino*, C. Bruschi, G. Callegari, S. Baiocchi, \\ G. Felicetti, C. Fracchia, C. Rampulla
}

Time course of exercise capacity, skeletal and respiratory muscle performance after heart-lung transplantation. N. Ambrosino, C. Bruschi, G. Callegari, S. Baiocchi, G. Felicetti, C. Fracchia, C. Rampulla. OERS Journals Ltd 1996.

ABSTRACT: Recipients of heart-lung transplantation (HLT) show reduced exercise capacity due to several pre- and postsurgical factors. The aim of this study was to evaluate the time course of exercise capacity, and skeletal and respiratory muscle performance in 11 patients ( 5 females and 6 males; age (mean \pm sD) $38 \pm 13$ yrs) undergoing HLT. All of the patients were admitted to our institution for a rehabilitation programme after surgery, and were followed-up for 18 months.

On admission, at discharge after an in-patient rehabilitation programme, and every 6 months, patients underwent evaluation of: lung function values; incremental treadmill exercise, 6 min walking distance (6-MWD); maximal inspiratory and expiratory pressures (MIP and MEP, respectively); and peak torque of isokinetic contraction of leg flexor and extensor muscles (IFX and IEX, respectively).

On admission, patients had: reduced lung volumes as assessed by vital capacity (VC) $(60 \pm 15 \%$ of predicted); reduced exercise capacity as assessed by peak oxygen consumption $\left(V^{\prime} \mathrm{O}_{2}\right.$,peak $)(40 \pm 12 \%$ pred $)$; reduced skeletal and respiratory muscle performance as assessed by IEX, IFX $(48 \pm 16$ and $28 \pm 12$ Newton-metres $(\mathbf{N} \times m)$, respectively) and by MIP and MEP (54 \pm 21 and $58 \pm 19 \mathrm{cmH}_{2} \mathrm{O}$, respectively). Ten patients completed the rehabilitation programme. At discharge, no significant change in dynamic and static lung volumes was observed. However, nonsignificant increases in MIP, MEP, IEX, IFX, 6-MWD and $V^{\prime} \mathrm{O}_{2}$,peak were recorded. After 6 and 12 months, indices of skeletal and respiratory muscle function and $V^{\prime} \mathrm{O}_{2}$,peak improved further, but still remained lower than normal values.

We conclude that in patients with heart-lung transplantation, skeletal and respiratory muscle function and exercise performance are reduced after surgery, that they may improve with time but are still less than normal after 18 months.

Eur Respir J., 1996, 9, 1508-1514.
Salvatore Maugeri Foundation IRCCS, Medical Center, Montescano, and *Gussago, Italy.

Correspondence: N. Ambrosino

Divisione di Pneumologia

Centro Medico

25064 Gussago (BS)

Italy

Keywords: Lung function tests physical training

pulmonary rehabilitation

respiratory muscle training

Received: January 171995

Accepted after revision February 21996
Heart-lung transplantation (HLT) has been shown to be effective as a treatment for fatal and severe cardiopulmonary diseases [1-3]. In addition to survival, one goal of performing HLT is improvement in quality of life [4]. Several factors contribute to the maximal work capacity achievable after transplantation. Before surgery, patients are usually debilitated from the primary disease and long-term inactivity [5]; and the unavoidable complications of allograft transplantation, mainly lung resection, and toxic effects of immunosuppressant therapy contribute to the reduced exercise capacity [6].

Numerous investigators have described the features of the cardiovascular response to steady-state exercise in heart and HLT recipients [7-11]. However, little information is currently available regarding the expected functional outcome [12-15], and not all studies have focused on results at a well-defined time-point. Even less information is available on skeletal and respiratory muscle function over time $[13,15,16]$. The aim of the present study was to evaluate exercise, skeletal and respiratory muscle performance over time in patients who have received a HLT and were followed-up for 18 months after surgery.

Materials and methods

\section{Patients}

From September 1991 until June 1993, 11 patients (5 females and 6 males; age (mean \pm SD) $38 \pm 13$ yrs (range

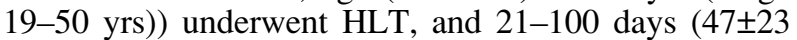
days) after discharge from the surgical unit were admitted to our institution for a rehabilitation programme. Their mean weight and height were $50 \pm 4 \mathrm{~kg}$ and $167 \pm 6 \mathrm{~cm}$, respectively. The underlying diseases were: Eisenmenger syndrome (4 patients); primary pulmonary hypertension (5); chronic obstructive pulmonary disease (COPD) (1); and bronchiectasis (1). None of the patients had undergone a structured preoperative rehabilitation programme. 
All patients were receiving maintenance immunosuppression with cyclosporin, azathioprine and prednisone.

Over two consecutive days, anthropometric, haematological, clinical and functional evaluations were performed at admission and at discharge from hospital, and at the nearest time-points to 6,12 and 18 months after the HLT. Patients were in a clinically stable condition without evidence of airway complications, and without having received therapy for acute rejection or infection during the month preceding the evaluation.

\section{Lung function tests}

Forced expiratory flows were evaluated by means of a water-sealed spirometer (Biomedin, Padova, Italy) with the patient in the seated posture. Static lung volumes were assessed using the helium dilution method. The predicted values were according to QuANJER [17], and were calculated in accordance with the recipient's characteristics. The transfer factor of the lungs for carbon monoxide (TL,CO) and the carbon monoxide transfer coefficient $(K \mathrm{CO})$ were determined by the single-breath method (Biomedin, Padova, Italy). An automated analyser (Radiometer ABL 300; Copenhagen, Denmark) was used to measure partial pressure of oxygen and carbon dioxide and oxygen saturation in blood samples from the radial artery for baseline assessments and from the ear lobe during exercise testing.

\section{Exercise testing}

Patients performed a progressive, incremental exercise test to a symptom-limited maximum on a motorized treadmill (Jaeger, Wurzburg, Germany) whilst breathing room air. Prior to each test, the patients rested standing upright on the treadmill for 5 min with a face mask in place for gas collection. Functional and metabolic data were determined at rest and during exercise by means of a computerized system (EOS-Sprint analyser; Jaeger, Wurzburg, Germany), mixed-expired gas data, minute ventilation $\left(V^{\prime} \mathrm{E}\right)$, tidal volume $(V \mathrm{~T})$, respiratory frequency $(f \mathrm{R})$, oxygen consumption $\left(V^{\prime} \mathrm{O}_{2}\right)$, carbon dioxide production $\left(V^{\prime} \mathrm{CO}_{2}\right)$ and respiratory exchange ratio $(\mathrm{R})$ were continuously monitored as average values of $30 \mathrm{~s}$ intervals. Electrocardiographic activity (ECG) was monitored continuously and systemic arterial blood pressure was registered every 3 min using a sphygmomanometer. Arterial oxygen tension $\left(\mathrm{Pa}, \mathrm{O}_{2}\right)$, arterial carbon dioxide tension $\left(\mathrm{Pa}, \mathrm{CO}_{2}\right)$, and $\mathrm{pH}$ were measured at rest and immediately before the end of the exercise test using arterialized blood samples from the ear lobe. After a period of warm-up walking at a comfortable pace $\left(1.6-2 \mathrm{~km} \cdot \mathrm{h}^{-1}, 0 \%\right.$ gradient), the treadmill was set at $3 \%$ gradient (elevation) and the speed increased on the basis of the patient's body weight to obtain a $30 \mathrm{~W}$ change. Thereafter, the gradient was increased by $3 \%$ every $3 \mathrm{~min}$ and the speed adjusted to obtain $30 \mathrm{~W}$ increment at each step. At rest ( 5 min after adaptation to the face mask) and during the last $10 \mathrm{~s}$ of each exercise step, the patients were asked to rate the "sense of dyspnoea" using a modified Borg Category Scale [18]. The exercise was stopped when the $V^{\prime} \mathrm{O}_{2}$,peak was achieved or when limited by symptoms.
Exercise performance was also assessed by the 6 min walking distance (6-MWD) test according to McGAviN et al. [19]. Verbal encouragement was given continuously during the test, but the patient was free to stop when desired. Three attempts were made, the best of which was considered in the data analysis. Results are expressed as actual distance walked in metres.

\section{Respiratory muscle strength}

Respiratory muscle strength was assessed by measuring maximal inspiratory and expiratory pressures (MIP and MEP, respectively) breathing at the level of functional residual capacity (FRC), according to the method of BLACK and HyATT [20], using a differential pressure transducer (range $\pm 300 \mathrm{cmH}_{2} \mathrm{O}$; Honeywell, Freeport, IL, USA). The subjects, comfortably seated and wearing a noseclip, performed maximal inspiratory and expiratory efforts, starting from FRC, against an obstructed mouthpiece with a small air leak to prevent closure of the glottis and connected to a tap that allowed the airway to be closed. The subjects were verbally encouraged to achieve maximal strength. The determinations were repeated until five measurements varying by less than $5 \%$ and sustained for at least $1 \mathrm{~s}$ were obtained; the best value achieved was considered in the data analysis. Normal values were according to BRUSCHI et al. [21].

\section{Skeletal muscle function}

The peak torque of isokinetic contraction at a test speed of $120^{\circ}$ per second of flexor (hamstring) and extensor (quadriceps) muscles of the leg (IFX and IEX, respectively) was measured by means of an isokinetic dynamometer (Cybex; Lumex Inc., Bay Shore, NY, USA) according to standard procedure, taking into account data from the dominant leg $[22,23]$. The better of two testing sequences was considered for analysis. Peak torque is measured in Newton-metres $(\mathrm{N} \times \mathrm{m})$. Twenty two sex-matched subjects, who had recently experienced a myocardial infarction without left ventricular dysfunction, served as controls. In these subjects, mean values of IEX and IFX were $117 \pm 22$ and $74 \pm 11 \mathrm{~N} \times \mathrm{m}$, respectively.

\section{Rehabilitation programme}

The in-hospital rehabilitation programme consisted of: 1) supervised incremental exercise, until achieving twice daily $30 \mathrm{~min}$ sessions of continuous treadmill walking at $70 \%$ of the load achieved on the incremental exercise test carried out at entry; 2) inspiratory muscle training: $10 \mathrm{~min}$ four times a day of inspiratory resistive breathing against a threshold device (Threshold; HealthScan Inc., USA), increasing the inspiratory load until a mouth pressure equal to $50 \%$ of MIP was attained [24]; and 3) abdominal muscle training and upper and lower limb training lifting a progressively increasing weight [25]. Nutritional programmes were prescribed when appropriate. After discharge, the patients were instructed to perform exercise (walking, cycling etc.) but no structured exercise programme was prescribed. 


\section{Statistical analysis}

An analysis of variance (ANOVA) test for repeated measurements was employed: 1) to evaluate differences in the indices considered compared with admission; and 2) to test a time effect during follow-up period. A linear regression analysis corrected for multiple comparisons was performed to correlate changes in lung, skeletal and respiratory muscle function and exercise capacity with duration of rehabilitation programme and hospitalization, changes in body weight and haemoglobin $(\mathrm{Hb})$ concentration. A p-value of less than 0.05 was considered to be significant.

\section{Results}

One patient died soon after admission due to cytomegalovirus pneumonia, before having performed any functional evaluation. One patient was found at admission to have bilateral phrenic nerve injury and was treated with nocturnal intermittent negative pressure ventilation using a poncho-wrap ventilator for 1 month. Ten patients performed the rehabilitation programme and after discharge were followed-up for 18 months. Hospitalization averaged $75 \pm 28$ days (range 28-106 days), during which patients performed the rehabilitation programme for $41 \pm$ 19 days (range $20-70$ days), i.e. $59 \pm 18 \%$ (range $20-76 \%$ ) of their stay in hospital.

\section{Lung function}

Preoperative lung function data of patients in the study were not available. The time course of lung function tests is presented in table 1. At admission, patients showed reduced static and dynamic volumes and TL,CO. At discharge from hospital, no significant changes in dynamic or static volumes, or in TL,CO were observed. A significant increase in VC was observed over time after discharge. At admission, patients were mildly hypoxaemic.
$P \mathrm{a}, \mathrm{O}_{2}$ was significantly increased at discharge and did not change throughout the follow-up.

\section{Exercise and muscle performance}

Changes in body weight, $\mathrm{Hb}$ concentration, respiratory and skeletal muscle performance and exercise tolerance are presented in table 2. On admission, patients were underweight and mildly anaemic. They showed reduced exercise capacity as assessed by $V^{\prime} \mathrm{O}_{2}$,peak and 6-MWD and in comparison to predicted or control values, and reduced respiratory and skeletal muscle performance as assessed by MIP, MEP, IEX and IFX. The single patient affected by bilateral phrenic nerve injury showed basal values of 17 and $16 \mathrm{cmH}_{2} \mathrm{O}$ (24 and $19 \%$ pred) for MIP and MEP, respectively.

Both body weight and $\mathrm{Hb}$ concentration progressively increased over time. In comparison to admission, this increase was significant starting from $1 \mathrm{yr}$ after HLT. Maximal body weight and $\mathrm{Hb}$ concentration (26 and $22 \%$ increase in comparison to admission, respectively) were observed at 18 months.

At discharge, patients showed an increase in MIP, MEP, IEX, IFX, 6-MWD and in $V^{\prime} \mathrm{O}_{2}$,peak which did not reach statistical significance. No significant relationship was found between changes in any functional parameter and duration of the rehabilitation programme or hospitalization, or changes in body weight or $\mathrm{Hb}$ concentration. Six months after HLT, improvement in IEX, IFX, 6-MWD and $V^{\prime} \mathrm{O}_{2}$, peak $\left(\mathrm{mL} \cdot \mathrm{kg} \cdot \mathrm{min}^{-1}\right)$ became significant and $V^{\prime} \mathrm{O}_{2}$,peak reached its highest level (a $38 \%$ increase in comparison to admission). The highest values of skeletal and respiratory muscle function indices were observed at 12 months $(38,72,71$ and $50 \%$ increase in comparison to admission for MIP, MEP, IEX and IFX, respectively). At that time, changes in MIP and MEP became significant. At 18 months, only 6-MWD showed a further increase to $51 \%$ of admission value.

Changes in these variables expressed as percentage of predicted (or control for IEX and IFX) are presented in

Table 1. - Ventilatory function, carbon monoxide transfer coefficient, transfer factor of the lung for carbon monoxide and arterial blood gas values at admission and discharge, and during follow-up

\begin{tabular}{|c|c|c|c|c|c|}
\hline & Admission & Discharge & 6 months & 12 months & 18 months \\
\hline $\mathrm{VC} \mathrm{L}$ & $2.3 \pm 0.5$ & $2.4 \pm 0.4$ & $2.6 \pm 0.7$ & $3 \pm 0.8 *$ & $3.1 \pm 0.8 *$ \\
\hline VC $\%$ pred & $60 \pm 15$ & $60 \pm 15$ & $70 \pm 17$ & $77 \pm 12 *$ & $81 \pm 11 *$ \\
\hline FEV1/FVC \% & $82 \pm 18$ & $78 \pm 15$ & $77 \pm 16$ & $75 \pm 18$ & $78 \pm 17$ \\
\hline FEV1 L & $2 \pm 0.4$ & $2 \pm 0.4$ & $2 \pm 0.4$ & $2.3 \pm 0.5$ & $2 \pm 0.6$ \\
\hline FEV1 \% pred & $56 \pm 12$ & $63 \pm 17$ & $64 \pm 15$ & $68 \pm 10$ & $67 \pm 28$ \\
\hline FRC \% pred & $85 \pm 15$ & $84 \pm 14$ & $87 \pm 17$ & $86 \pm 18$ & $83 \pm 29$ \\
\hline TLC $\%$ pred & $70 \pm 11$ & $75 \pm 9$ & $71 \pm 15$ & $84 \pm 12$ & $78 \pm 12$ \\
\hline KCO $\mathrm{mmol} \cdot \mathrm{min} \cdot \mathrm{kPa}^{-1} \cdot \mathrm{L}^{-1}$ & $1.07 \pm 0.3$ & $1.15 \pm 0.4$ & $1.04 \pm 0.17$ & $1.09 \pm 0.17$ & $1.27 \pm 0.24$ \\
\hline$\%$ pred & $52 \pm 13$ & $55 \pm 2$ & $49 \pm 8$ & $53 \pm 9$ & $62 \pm 12$ \\
\hline$T \mathrm{~L}, \mathrm{CO} \quad \mathrm{mmol} \cdot \mathrm{min} \cdot \mathrm{kPa}^{-1}$ & $3.6 \pm 0.8$ & $3.6 \pm 0.8$ & $3.8 \pm 0.6$ & $4.3 \pm 0.9$ & $5.2 \pm 1.3$ \\
\hline$\%$ pred & $37 \pm 6$ & $41 \pm 16$ & $39 \pm 6$ & $46 \pm 10$ & $54 \pm 14$ \\
\hline$P \mathrm{a}, \mathrm{O}_{2} \quad \mathrm{kPa}$ & $10.4 \pm 1.3$ & $11.6 \pm 1.3^{*}$ & $11.6 \pm 1.3^{*}$ & $11.7 \pm 1.4 *$ & $11 \pm 1.8$ \\
\hline $\mathrm{Pa}_{\mathrm{a}, \mathrm{CO}_{2} \quad \mathrm{kPa}}$ & $4.8 \pm 0.8$ & $4.7 \pm 0.6$ & $4.9 \pm 0.8$ & $4.7 \pm 0.5$ & $4.6 \pm 0.5$ \\
\hline${\mathrm{Sa}, \mathrm{O}_{2}}_{2} \%$ & $95.4 \pm 0.4$ & $96.5 \pm 1$ & $97 \pm 1.3 *$ & $96 \pm 1.3^{*}$ & $96 \pm 2$ \\
\hline
\end{tabular}

Values are presented as mean \pm SD. VC: vital capacity; FEV1: forced expiratory volume in one second; FVC: forced vital capacity; FRC: functional residual capacity; TLC: total lung capacity; KCO: carbon dioxide transfer coefficient; TL,CO: transfer factor of the lung for carbon monoxide; $\mathrm{Pa}_{\mathrm{a}} \mathrm{O}_{2}$ and $\mathrm{P}_{\mathrm{a}}, \mathrm{CO}_{2}$ : arterial oxygen and carbon dioxide tension, respectively; $\mathrm{Sa}, \mathrm{O}_{2}$ : arterial oxygen saturation; $\%$ pred: percentage of predicted value. $*$ : $\mathrm{p}<0.05$, compared with value at admission. 
Table 2. - Body weight, haemoglobin concentration, muscle and exercise performance at admission and discharge, and during follow-up

\begin{tabular}{|c|c|c|c|c|c|}
\hline & Admission & Discharge & 6 months & 12 months & 18 months \\
\hline $\mathrm{Hb} g \cdot \mathrm{dL}^{-1}$ & $9.3 \pm 0.7$ & $10.2 \pm 3.5$ & $10.5 \pm 1.4$ & $11 \pm 2.2 *$ & $13 \pm 2 *$ \\
\hline Weight $\mathrm{kg}$ & $50 \pm 5$ & $50 \pm 4$ & $54 \pm 7$ & $60 \pm 7 * * *$ & $63 \pm 9 * * *$ \\
\hline $\mathrm{MIP} \mathrm{cmH}_{2} \mathrm{O}$ & $54 \pm 21$ & $60 \pm 23$ & $69 \pm 26$ & $75 \pm 17 *$ & $65 \pm 16$ \\
\hline MEP $\mathrm{cmH}_{2} \mathrm{O}$ & $58 \pm 19$ & $70 \pm 18$ & $78 \pm 9$ & $100 \pm 49 * * *$ & $82 \pm 31 * * *$ \\
\hline IEX $\mathrm{N} \times \mathrm{m}$ & $48 \pm 16$ & $55 \pm 16$ & $86 \pm 18 * * *$ & $82 \pm 16 * * *$ & $78 \pm 20 * * *$ \\
\hline IFX $\quad \mathrm{N} \times \mathrm{m}$ & $28 \pm 12$ & $33 \pm 11$ & $35 \pm 10^{*}$ & $44 \pm 7 * * *$ & $42 \pm 10 * * *$ \\
\hline 6-MWD m & $351 \pm 66$ & $422 \pm 69$ & $481 \pm 76 * * *$ & $511 \pm 100 * * *$ & $530 \pm 91 * * *$ \\
\hline$V^{\prime} \mathrm{O}_{2}$, peak $\mathrm{mL} \cdot \mathrm{kg} \cdot \mathrm{min}^{-1}$ & $14.2 \pm 4$ & $18.2 \pm 6$ & $19.6 \pm 6^{*}$ & $18.9 \pm 3.5$ & $15.7 \pm 4$ \\
\hline$V^{\prime} \mathrm{O}_{2}$,peak $\%$ pred & $40 \pm 13$ & $55 \pm 4$ & $56 \pm 18$ & $51 \pm 20$ & $48 \pm 14$ \\
\hline
\end{tabular}

Values are presented as mean $\pm \mathrm{SD}$. Hb: haemoglobin concentration; MIP: maximal static inspiratory pressure; MEP: maximal static expiratory pressure; IEX: peak torque of isokinetic contraction of extensor leg muscles; IFX: peak torque of isokinetic contraction of flexor leg muscles; 6-MWD: 6 min walking distance; $V^{\prime} \mathrm{O}_{2}$,peak: peak oxygen consumption; \% pred: percentage of predicted value. $*: \mathrm{p}<0.05$; and $* * *: \mathrm{p}<0.001$, compared with value at admission.

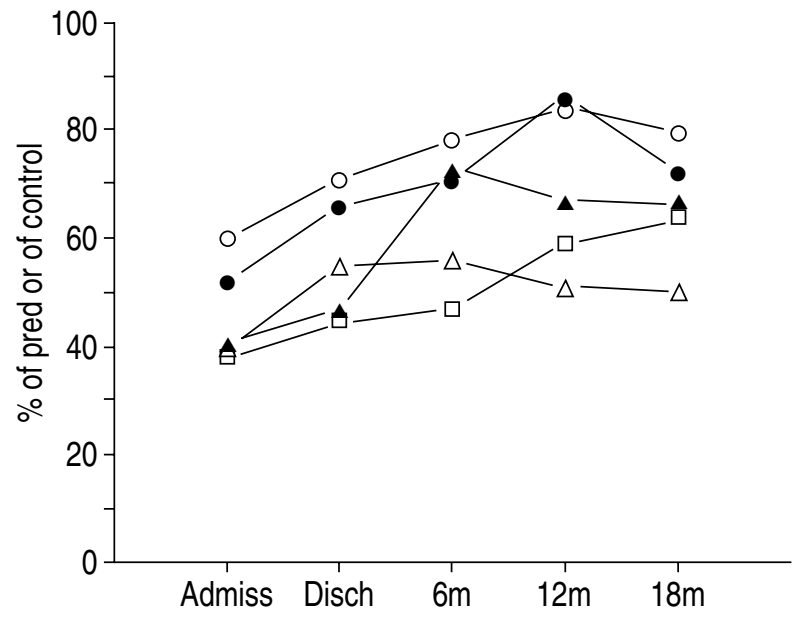

Fig. 1. - Time course of exercise and muscle performance. Values in percentage of predicted (\% pred) or of control (see text). $-\mathrm{O}-$ :

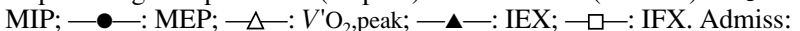
values assessed at hospital admission; Disch: values assessed at discharge; $6 \mathrm{~m}, 12$, and $18 \mathrm{~m}$ : values assessed at 6,12 and 18 months after surgery, respectively. MIP: maximal static inspiratory pressure; MEP: maximal static expiratory pressure; IEX: peak torque of isokinetic contraction of extensor leg muscles; IFX: peak torque of isokinetic contraction of flexor leg muscles; $V^{\prime} \mathrm{O}_{2}$, peak: peak oxygen consumption.

figure 1. The highest increases with time were observed at 12 months in MIP and MEP (to 84 and $86 \%$ pred, respectively). At all time-points, all of these measurements were reduced in comparison to predicted or control values.

In table 3 , the time course of cardiopulmonary parameters at rest and at maximum exercise are presented. At admission, patients had a more elevated mean resting heart rate (HR) than predicted. All patients stopped the exercise test due to leg muscle fatigue. Maximum $\mathrm{HR}$ and $V^{\prime} \mathrm{E}$ were reduced. Maximum HR, but not $V^{\prime} \mathrm{E}$, significantly increased at discharge and further increased 6 and 12 months after surgery. No significant desaturation with exercise occurred at any time.

\section{Discussion}

To our knowledge, this is the first report on changes of skeletal and respiratory muscle function over time in recipients of heart-lung transplantation. After HLT, cardiorespiratory function, respiratory and skeletal muscle performance and exercise tolerance were below the predicted or control values. Although, after hospitalization, these parameters showed an improvement which was well-maintained for at least 18 months, they were still significantly below predicted values.

\section{Lung function tests}

Dynamic flows, TLC (\% pred) and TL,CO were low compared with earlier reports [13, 16, 26-28]. This poor lung function after transplantation may have affected the exercise and muscle performance.

\section{Exercise tolerance}

Maximal tolerable exercise capacity has been shown to be reduced in HLT patients. Despite the fact that they were studied in stable clinical condition, HLT patients only achieved $V^{\prime} \mathrm{O}_{2}$,peak values of approximately $40-60 \%$ predicted. On admission, the patients showed a reduced exercise capacity, in keeping with the literature $[6,11$, 12]. A less severe reduction in aerobic work capacity has been found in heart transplant patients [8-10, 29, 30], suggesting that cardiovascular function poses the greater restraining influence on muscular effort in these patients, but other factors may be involved. At discharge, $V^{\prime} \mathrm{O}_{2}$,peak increased to $55 \pm 4 \%$ pred, which is in keeping with the values found by KIMOFF et al. [15], and by LeVy et al. [31]. In this latter series, the exercise evaluation was performed $7.4 \pm 2.2$ months after surgery, their patients also having performed a supervised graded aerobic exercise programme. Interestingly enough $V^{\prime} \mathrm{O}_{2}$,peak did not return to normal values after 18 months. Similar results have recently been found by ORENS et al. [32] in single and double lung transplantation recipients.

The levels of the $V^{\prime} \mathrm{E} / V^{\prime} \mathrm{O}_{2}$ ratio at maximal work found in our study are similar to those of LeVY et al. [31] and THEODORE et al. [12], and showed a constant trend to decrease over the follow-up. Exercise in HLT is associated with excessive hyperventilation in relation to the rate of oxygen uptake $[15,33]$. This may represent an effect of prolonged confinement to bed. In HLT, Grassi et al. 


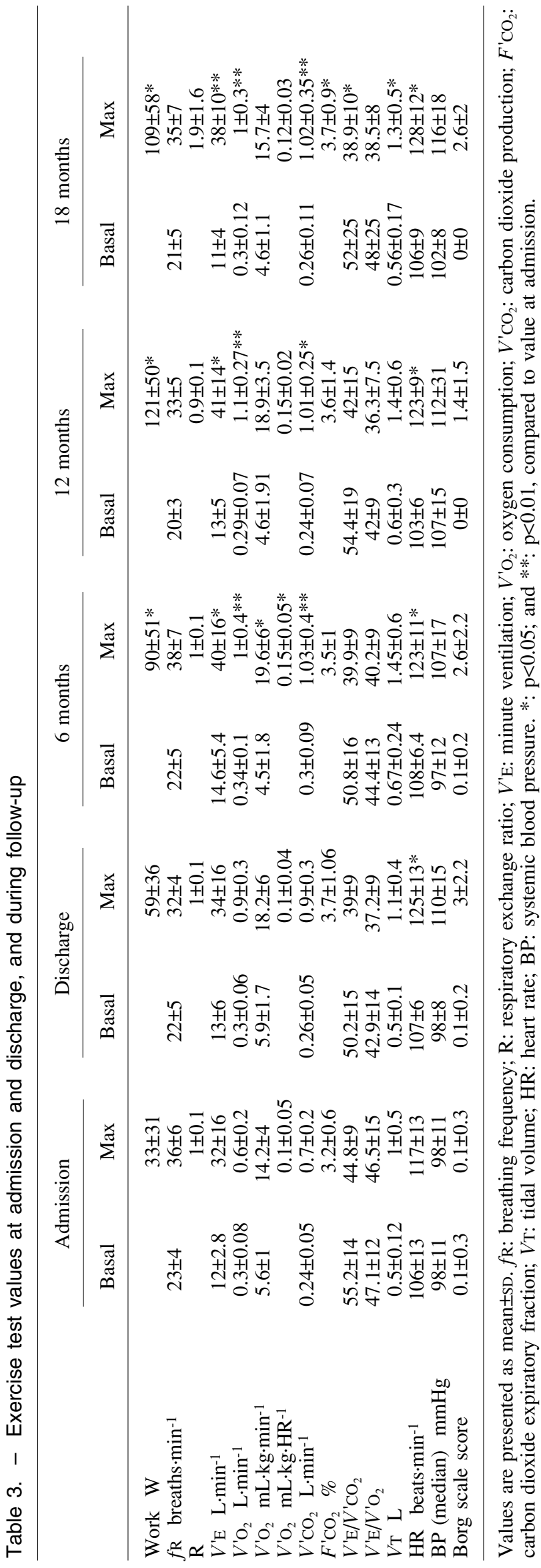

[11] found that the ventilatory response is substantially preserved despite lung denervation, confirming a previous study by CerRetelli et al. [8] in heart transplantation recipients. These authors found that the limitation of peak exercise appeared to be imposed by a reduced maximal cardiac performance. The proportional contributions of $V \mathrm{~T}$ and $f \mathrm{R}$ were within normal limits both at rest and at maximal exercise levels and did not change with time. In some, but not all, HTL recipients studied by GRASSI et al. [11], breathing pattern during steadystate exercise was similar to that of heart transplantation recipients and to normal untrained subjects. A previous suggestion that there is an inco-ordination of $V \mathrm{~T}$ and $f \mathrm{R}$ resulting from the loss of intrapulmonary receptors was not confirmed when HLT patients were compared with normal subjects during peak exercise $[13,15]$.

Arterial blood gas values during maximum exercise can be used as an index of the efficiency of pulmonary gas exchange. Under these conditions, the transplanted lungs of our patients were essentially normal, perhaps indicating that the integrating function required for matching ventilation and perfusion is intrapulmonary and autoregulatory in nature, and that an external nerve supply is not a crucial requirement for regulating gas exchange within the lung.

Many factors may influence exercise performance after transplantation. Some of these antedate the procedure, such as age of onset and duration of the pretransplant illness, as well as physical deconditioning and psychological factors associated with long-term debilitation [4-6]. Further postoperative negative influences on recovery could arise from cardiac denervation [7], the short- and long-term complications of allograft transplantation, and the adverse reactions of long-term immunosuppression [34]. Reduction in exercise capacity has been related to acute and chronic anaemia. This may be induced by most of the drugs used, as in our patients, for immunosuppression such as azathioprine or cyclosporin, with different mechanisms [35, 36]. However, although at admission our patients showed a reduction in haemoglobin concentration, anaemia was progressively corrected over time, whilst exercise capacity did not improve further after the 6th month, clearly indicating that other factors may have contributed to the observed reduction.

We have found no report on 6-MWD in HLT. In patients with end-stage pulmonary fibrosis submitted to single-lung transplantation, GROSSMAN et al. [37] found values of 6-MWD quite similar to ours. Interestingly, 6MWD was the one parameter improving at 18th month in comparison to admission, behaving differently from the $V^{\prime} \mathrm{O}_{2}$,peak. The improvements in 6-MWD in our patients may be, at least in part, related to a learning effect. The 6-MWD is dependent on the physical capacity of patients and may be used as an index of their ability to cope with daily activities [19].

\section{Respiratory muscle function}

Inspiratory and expiratory muscles were similarly affected at admission. Improvements in inspiratory and expiratory muscle strength as assessed by MIP and MEP were similar. The rehabilitation programme included both specific inspiratory and abdominal muscle training, but 
at discharge increases in MIP and MEP were 11 and $21 \%$ of the admission value, respectively. Many factors may influence the results of respiratory muscle strength assessment. Motivation and learning may affect measurements [38], distortion of rib cage due to surgery, anaemia, and steroid-induced myopathy [39] may reduce respiratory muscle strength. Our data are in keeping with those of ScIURBa et al. [13] and SANDERS et al. [16] in HLT patients. The MIP of our patients measured after 6 months are also in agreement with the findings of WiLLIAMS et al. [40], who performed MIP assessments in single and double transplant recipients 3 months after surgery. In contrast to our results, KIMOFF et al. [15] found mean values of MIP greater in four HLT patients than in their control population 3-9 months after surgery. We found no reports on MEP assessment in HLT. Comparison with other studies is difficult, due to different times of evaluation, different methods of measurement, different rehabilitation programmes, if any, prevalence of surgery-induced phrenic nerve lesions and prevalence of infectious and rejection episodes.

\section{Skeletal muscle function}

General muscle performance was evaluated by means of the assessment of the peak torque of flexor and extensor leg muscle during isokinetic exercise [22]. Isokinetic exercise is a dynamic type of resistive exercise. Existing studies identify, but do not adequately define, a correlation between torque values and age, sex and conditioning state [22, 41, 42]. Postoperative reduction in IEX and IFX was similar and increases over time were parallel. Chronic preoperative inactivity, psychological factors, steroid myopathy and drug effects may reduce skeletal muscle function in HLT patients [34].

Although preoperative rehabilitation is considered important to achieve good lung function and good exercise performance after lung transplantation [25], our patients did not perform such programmes before surgery due to the fact that they were referred to us only after transplantation. With regard to respiratory muscle strength, $V^{\prime} \mathrm{O}_{2}$,peak, quadriceps and hamstring torque values as percentage of predicted (or control) (fig. 1) all the considered parameters showed a postoperative reduction ranging $40-60 \%$ compared to normal subjects. The greatest improvements were observed in respiratory muscle strength. This result might be related to the rehabilitation programme. Although, for ethical reasons, we did not study a control population, we feel that a rehabilitation programme might be useful in the postoperative treatment of HLT patients. Due to unavoidable complications of HLT, such as thoracic wound, opportunistic infections and acute lung rejection episodes, patients with HLT are often not able to perform a continuous rehabilitation programme. In this regard, our patients performed a rehabilitation programme over a very wide range of periods (20-70 days).

To our knowledge, there is no report on the effects of the single components of a rehabilitation programme in lung transplant recipients. Furthermore, in the one study reporting MIP increase with time, single and double transplant recipients performed postoperative rehabilitation programmes consisting only of aerobic exercise, without any specific inspiratory muscle training [40]. For these reasons, although the clinical benefits of exercise training [43], inspiratory muscle training [44] and weightlifting training [45] are well-documented both in normal and in pathological conditions, conclusions on the possible effects of rehabilitation in HLT can only be speculative.

In conclusion, in recipients of heart-lung transplantation, skeletal and respiratory muscle function and exercise performances are reduced after surgery, may improve with time but are still below normal values after 18 months. The benefits of rehabilitation programmes should be evaluated with controlled studies.

\section{References}

1. Griffith BP, Hardesty RL, Trento IL, et al. Heart-lung transplantation: lessons learned and future hopes. Ann Thorac Surg 1987; 43: 6-16.

2. Hutter JA, Despins P, Higenbottam TW, Stewart S, Wallwork J. Heart-lung transplantation: better use of resources. Am J Med 1988; 85: 4-11.

3. Kriett JM, Kaye MP. The registry of the international society for heart and lung transplantation: eighth official report - 1991. J Heart Lung Transplant 1991: 10: 491498.

4. Craven JL, Bright J, Dear CL. Psychiatric, psychosocial and rehabilitative aspects of lung transplantation. Clin Chest Med 1990; 11: 247-257.

5. Hung J, Goldwater D, Convertino VA, McKillop JH, Goris ML, Debusk RF. Mechanisms of decreased exercise capacity after bed rest in normal middle-aged men. Am J Cardiol 1983; 51: 344-348.

6. Otulana BA, Higenbottam TW, Wallwork J. Causes of exercise limitation after heart-lung transplantation. $J$ Heart Lung Transplant 1992; 11: S 244-251.

7. Kavanagh T, Yacoub HM, Mertens DJ, Kennedy J, Campbell RB, Sawyer P. Cardiorespiratory responses to exercise training after orthotopic cardiac tranplantation. Circulation 1988; 77: 162-171.

8. Cerretelli $\mathrm{P}$, Grassi B, Colombini A, Carù B, Marconi C. Gas exchange and metabolic transients in heart transplant recipients. Respir Physiol 1988; 74: 355-371.

9. Meyer M, Cerretelli P, Marconi C, Rieu M, Cabrol Ch. Cardiorespiratory adjustment to exercise after cardiac transplantation. In: Reinhart K, Eyrich K, eds. Clinical Aspects of $\mathrm{O}_{2}$ Transport and Tissue Oxygenation. Berlin, Springer-Verlag, 1989; pp. 477-499.

10. Cerretelli P, Marconi C, Meyer M, Ferretti G, Brassi B. Gas exchange kinetics in heart transplant recipients. Chest 1992; 101: 199S-205S.

11. Grassi B, Ferretti G, Xi L, et al. Ventilatory response to exercise after heart and lung denervation in humans. Respir Physiol 1993; 92: 289-304.

12. Theodore J, Morris AJ, Burke CM, et al. Cardiopulmonary function at maximum tolerable constant work rate exercise following human heart-lung transplantation. Chest 1987; 92: 433-439.

13. Sciurba FC, Owens GR, Sanders MH, et al. Evidence of an altered pattern of breathing during exercise in recipients of heart-lung transplants. N Engl J Med 1988; 319 : 1186-1192.

14. Banner NR, Lloyd MH, Hamilton RD, Innes JA, Guz A, Yacoub MH. Cardiopulmonary response to dynamic exercise after heart and combined heart-lung transplantation. Br Heart $J$ 1989; 61: 215-223. 
15. Kimoff RJ, Cheong TH, Cosio MG, Guerraty A, Levy RD. Pulmonary denervation in humans: effects on dyspnoea and ventilatory pattern during exercise. Am Rev Respir Dis 1990; 142: 1034-1040.

16. Sanders MH, Owens GR, Sciurba FC, et al. Ventilation and breathing pattern during progressive hypercapnia and hypoxia after human heart-lung transplantation. Am Rev Respir Dis 1989; 140: 38-44.

17. Quanjer PhH, Tammelin GJ, Cotes JE, Pedersen OF, Peslin R, Yernault J-C. Lung volumes and forced ventilatory flows. Report Working Party "Standardization of Lung Function Tests". European Coal and Steel Community. Eur Respir J 1993; 6 (Suppl. 16): 5-40.

18. Borg G. Psychophysical basis of perceived exertion. Med Sci Sports Exerc 1982; 14: 377-381.

19. McGavin CR, Gupta SP, McHardy GJR. Twelve minute walking test for assessing disability in chronic bronchitis. BMJ 1976; 1: 822-823.

20. Black L, Hyatt R. Maximal airway pressures: normal values and relationship to age and sex. Am Rev Respir Dis 1969; 99: 696-702.

21. Bruschi C, Cerveri I, Zoia MC, et al. Reference values of maximal respiratory mouth pressures: a populationbased study. Am Rev Respir Dis 1992; 146: 790-793.

22. Wyatt MP, Edwards AM. Comparison of quadriceps and hamstring torque values during isokinetic exercise. $J$ Orthop Sports Phys Ther 1981; 3: 202-210.

23. Felicetti G, Zelaschi F, Di Patrizi S. Endurance tests during isokinetic contraction: reliability of functional parameters. Isokin Exer Sci 1994; 4: 76-80.

24. Larson JL, Kim MJ, Sharp JT, Larson DA. Inspiratory muscle training with a pressure threshold breathing device in patients with chronic obstructive pulmonary disease. Am Rev Respir Dis 1988; 138: 689-696.

25. Biggar DG, Malen JF, Trulock EP, Cooper JD. Pulmonary rehabilitation before and after lung transplantation. In: Casaburi R, Petty T, eds. Principles and Practice of Pulmonary Rehabilitation. Philadelphia, W.B. Saunders, 1993; pp. 459-477.

26. Dawkins KD, Jameson SW, Hunt SA, et al. Long-term results, hemodynamics, and complications after combined heart and lung transplantation. Circulation 1985; 71: 919-926.

27. Sciurba FC, Owens GR, Sanders MH, Costantino JP, Paradis IL, Griffith BP. The effect of obliterative bronchiolitis on breathing pattern during exercise in recipients of heart-lung transplants. Am Rev Respir Dis 1991; 144: 131-135.

28. Tamm M, Higenbottam TW, Dennis CM, Sharples LD, Wallwork J. Donor and recipient predicted lung volume and lung size after heart-lung transplantation. Am J Respir Crit Care Med 1994; 150: 403-407.

29. Savin WM, Haskell WL, Schroeder JS, Stinson EB. Cardiorespiratory responses of cardiac transplant patients to graded, symptom-limited exercise. Circulation 1980; 62: $55-60$.

30. Jahnke AW, Leyh R, Guha M, Sievers HH, Bernhard A.
Time course of lung function and exercise performance after heart transplantation. J Heart Lung Transplant 1994; 13: 412-417.

31. Levy RD, Ernst P, Levine SM, et al. Exercise performance after lung transplantation. J Heart Lung Transplant 1993; 12: 27-33.

32. Orens JB, Becker FS, Lynch JP, Christensen PJ, Deeb GM, Martinez FJ. Cardiopulmonary exercise testing following allogenic lung transplantation for different underlying disease states. Chest 1995; 107: 144-149.

33. Otulana BA, Higenbottam TW, Scott JP, Wallwork J. A possible role for mixed venous blood changes in the hyperventilation of exercise in heart-lung transplantation recipients. Chest 1990; 97: 88S-89S.

34. Bowyer SL, LaMohte MP, Hollister JR. Steroid myopathy: incidence and detection in a population with asthma. J Allergy Clin Immunol 1985; 76: 234-242.

35. Greenberg A, Egel JW, Thompson ML, et al. Early and late forms of cyclosporine nephrotoxicity: studies in cardiac transplant recipients. Am J Kidney Dis 1987; 9: 12-22.

36. Woodson RD, Wills RE, Lenfant C. Effect of acute and established anemia on $\mathrm{O}_{2}$ transport at rest, submaximal and maximal work. J Appl Physiol: Respirat Environ Exercise Physiol 1978; 44: 36-43.

37. Grossman RF, Frost A, Zamel N, et al. Results of single-lung transplantation for bilateral pulmonary fibrosis. N Engl J Med 1990; 322: 727-733.

38. Fiz JA, Montserrat JM, Picado C, Plaza V, Agusti-Vidal A. How many manoeuvres should be done to measure maximal inspiratory mouth pressure in patients with chronic airflow obstruction? Thorax 1989; 44: 419-421.

39. Wilcox PG, Hards JM, Bockold K, Bressler B, Pardy RL. Pathologic changes and contractile properties of the diaphragm in corticosteroid myopathy in hamsters: comparison to peripheral muscle. Am J Respir Cell Mol Biol 1989; 1: 191-199.

40. Williams TJ, Patterson GA, McClean PA, Zamel N, Maurer JR. Maximal exercise testing in single- and double-lung transplant recipients. Am Rev Respir Dis 1992; 145: 101-105.

41. Miyashita M, Kanchisa H. Dynamic peak torque related to age, sex and performance. Res $Q$ 1979; 50: 249255.

42. Murray PM, Gardner GM, Mollinger LA, Sepic SB. Strength of isometric and isokinetic contractions-knee muscles of men ages 20-86. Phys Ter 1980; 60: 412-419.

43. Cox NJM, Van Herwaarden CLA, Folgering H, Binkhorst RA. Exercise and training in patients with chronic obstructive lung disease. Sports Med 1988; 6: 180-192.

44. Rampulla C, Ambrosino N. Inspiratory muscle training and rest in COPD patients. Eur Respir Rev 1991; 1: 490-497.

45. Simpson K, Killian K, McCartney N, Stubbing DG, Jones NL. Randomised controlled trial of weightlifting exercise in patients with chronic airflow limitation. Thorax 1992; 47: 70-75. 